\title{
Outcomes of repeat balloon assisted enteroscopy in small-bowel bleeding
}

\section{(ㄷ)(잉}

Authors

Badr Al-Bawardy ${ }^{1}$, Guilherme Piovezani Ramos², Ryan J. Lennon³ , Emmanuel Gorospe', Louis M. Wong Kee Song',

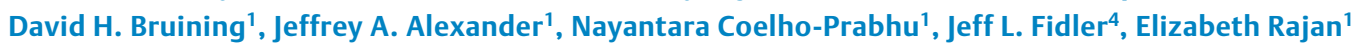

Institutions

1 Division of Gastroenterology and Hepatology, Mayo Clinic, Rochester, MN, USA

2 Department of Internal Medicine, Mayo Clinic, Rochester, MN, USA

3 Division of Biomedical Statistics and Informatics, Mayo Clinic, Rochester, MN, USA

4 Department of Radiology, Mayo Clinic, Rochester, MN, USA

submitted 6.10.2017

accepted after revision 20.2.2018

Bibliography

DOI https://doi.org/10.1055/a-0599-6085 |

Endoscopy International Open 2018; 06: E694-E699

(C) Georg Thieme Verlag KG Stuttgart · New York

ISSN 2364-3722

Corresponding author

Elizabeth Rajan, MD, Division of Gastroenterology \& Hepatology, Mayo Clinic, 200 First Street, S.W., Rochester, MN 55905, USA

Fax: +1-507-284-0538

Rajan.Elizabeth16@mayo.edu

\section{ABSTRACT}

Background/aims The rate of recurrent small-bowel bleeding (SBB) remains high despite the advent of balloon assisted enteroscopy (BAE). The study aims were to determine: (1) the diagnostic and therapeutic yields, and adverse event rate of repeat $\mathrm{BAE}$ in $\mathrm{SBB}$, and (2) the predictors of a positive repeat BAE.

Methods A retrospective review of a BAE database was conducted. Patients who had $>1$ BAE for SBB were included. Primary outcomes were diagnostic yield, therapeutic yield, and adverse events of repeat BAE. Secondary outcomes were predictors of a positive repeat BAE.

Results A total of 175 patients ( $55 \%$ men; mean age $64.1 \pm$ 16.3 years) were included. The diagnostic and therapeutic yields of repeat BAE were $55 \%$ and $42 \%$, respectively. Repeat BAE adverse events occurred in $5 \%$ with self-limited abdominal pain being most common. Patients with a positive repeat $B A E$ were significantly older than the negative group $(68.6 \pm 13.9$ vs. $60.9 \pm 17.1 ; P=0.001)$ and were more likely to have cardiac comorbidities (OR 2.4, $95 \% \mathrm{Cl}$ : $1.3-4.6$; $P=0.01$ ), chronic kidney disease (OR 2.3, $95 \% \mathrm{Cl}$ : $1.1-4.9 ; P=0.04)$, chronic obstructive pulmonary disease (OR 3.3, 95\%Cl: $1.3-8.1 ; P=0.01$ ), positive initial BAE (OR 3.6, $95 \% \mathrm{Cl}: 1.9-6.8 ; P<0.001)$, and antegrade procedure (OR 3.3, $95 \% \mathrm{Cl}: 1.7-6.1$; $P<0.001$ ). On multivariate analysis, a positive initial BAE and antegrade route were the only significant predictive factors.

Conclusions Performing a repeat BAE for SBB appears safe and provided modest yields. A positive initial BAE and antegrade route were predictive of a positive repeat BAE.

\section{Background}

Small-bowel bleeding is more recently defined as gastrointestinal bleeding (GIB) located between the ampulla and ileocecal valve. It has since replaced the term obscure GIB which is now reserved for patients without an identifiable source of bleeding despite small-bowel evaluation [1]. Small-bowel bleeding accounts for $5-10 \%$ of all GIB episodes [2-4].

Since it was first described in 2001, balloon assisted enteroscopy (BAE) and other device assisted enteroscopies have be- come central in the management of small-bowel bleeding [5]. It serves as both a diagnostic and therapeutic modality. Despite directed therapy, the risk of rebleeding, especially in the setting of small-bowel angioectasia, remains substantial. Long-term follow-up studies have illustrated a rebleeding rate that approaches $46 \%$ [6-8]. Management of such patients can be challenging as it often involves multiple endoscopic procedures, blood transfusions, and hospitalizations. The optimal management strategy for rebleeding after device assisted enteroscopy is still not well defined. A small series of repeat dou- 
ble balloon enteroscopy (DBE) in 32 obscure GIB patients demonstrated a diagnostic yield of $53 \%$ with a higher yield in patients with prior positive DBE [9].

Our study aims were to (1) determine the diagnostic yield, therapeutic yield, and adverse event rate of repeat BAE in a large cohort of patients with small-bowel bleeding, and (2) assess the clinical and endoscopic predictors of a positive repeat BAE.

\section{Methods}

We performed a retrospective review of a prospectively maintained BAE database at our institution from September 2006 to August 2016. The study was approved by the Institutional Review Board. We included patients who had $>1$ BAE for an indication of overt or occult suspected small-bowel bleeding. Small-bowel bleeding was defined as GIB in patients with a normal (absence of a bleeding source) upper endoscopy and colonoscopy. Overt bleeding was defined as melena or hematochezia, and occult bleeding was defined as iron deficiency anemia and/or positive fecal occult blood.

Balloon assisted enteroscopy was performed with either double balloon (EN-450T5, Fujinon, Inc., Saitama, Japan) or single balloon (SIF-Q180, Olympus Corp., Center Valley, Pennsylvania, United States) enteroscopes. The decision to use single versus double balloon and antegrade or retrograde approach was guided by the presumed location of the culprit lesion detected by small-bowel imaging when available and/or by the primary gastroenterologist providing patient care. Diagnostic yield was defined as detecting a probable culprit lesion and therapeutic yield was defined as endotherapy of a probable culprit lesion during BAE. A probable culprit lesion was defined as either an actively bleeding lesion or one that was the likely source of bleeding. A BAE exam was considered positive if endotherapy was applied.

Data was abstracted for patient demographics, clinical presentation, anticoagulant and antiplatelet medications, and BAE procedural details (both initial and repeat BAE). Medical comorbidity data, including cardiac (aortic stenosis, left ventricular assist device therapy, heart failure, and prosthetic heart valves), chronic kidney disease (CKD), liver cirrhosis/portal hypertension, and chronic obstructive pulmonary disease (COPD), were collected. Data was also abstracted from smallbowel imaging modalities of capsule endoscopy (CE) and computed tomography enterography (CTE). The primary outcomes measured were diagnostic yield, therapeutic yield, and adverse events of repeat BAE. The secondary outcome was to identify predictors of a positive repeat BAE.

\section{Statistical analysis}

We used JMP (SAS Institute Inc., Cary, North Carolina, United States) and R (R Foundation for Statistical Computing, Vienna, Austria) statistical software for data analysis. Group comparisons were tested using Pearson's chi-squared test for categorical data and Student's $t$ test for continuous data. Multiple logistic regression was used to fit a model for therapeutic repeat BAE. The multivariable model consisted of age, cardiac comor- bidities, CKD, positive imaging (CE and $C T E$ ) results before initial $B A E$, positive diagnostic yield at initial $B A E$, and use of the antegrade route on the repeat BAE. All hypothesis tests were two-tailed and a $P$ value $<0.05$ was considered statistically significant.

\section{Results}

A total of 1383 patients underwent 1920 BAE procedures for various indications at our institution during the study period. In total, 369 patients had more than $1 \mathrm{BAE}$ performed. A total of 175 patients had more than $1 \mathrm{BAE}$ for the indication of overt or occult small-bowel bleeding and were included in the analysis. The mean age was $64.1 \pm 16.3$ years and 96 (55\%) were men.

\section{Initial BAE}

Clinical presentation before initial BAE included occult bleeding (50\%), melena (40\%), and hematochezia (10\%) ( Table 1). Capsule endoscopy was performed in $77 \%(n=134)$ of the cohort and was positive in $69 \%(n=92)$. In the remaining 41 patients who did not undergo CE, 19 patients underwent CTE which was positive in 11 patients (58\%) ( $\triangleright$ Table 1 ).

BAE was performed in the antegrade route in $78 \%(n=136)$ and via DBE in $93 \%(n=162)$ of cases. The diagnostic yield of initial BAE was $49 \%(n=85)$ and therapeutic yield was $46 \%$ $(n=81)$. Angioectasia $(n=75)$ was the most common finding ( $\vee$ Table 1). Multiple angioectasias were noted in 51 patients and active bleeding was observed in 18 of these patients. Initial CE and initial BAE agreed in $61 \%(n=82)$. In $31 \%(n=41)$, the initial CE was positive and the initial BAE was negative, while in $8 \%$ $(n=11)$, the initial CE was negative and the initial BAE was positive. The Cohen's kappa statistic for agreement was 0.23 .

\section{Repeat BAE}

The median time to repeat BAE was 41 days (range $0-1758$ days). Occult bleeding was noted in $49 \%$, melena in $41 \%$, and hematochezia in $10 \%$. Before repeat BAE, only 21 patients underwent repeat CE which was positive in $17(77 \%)$ and CTE was performed in 12 patients and was positive in 7 (47\%).

Repeat BAE was performed via double balloon in $95 \%(n=$ 167). The antegrade route was utilized in $46 \%(n=81)$ and in the same route as initial BAE in $35 \%(n=62)$. Repeat BAE was performed in the opposite direction in 71 patients who had a negative initial BAE (79\%) to identify a bleeding source, while repeat $B A E$ was performed in the same route in 43 patients with a positive initial BAE (51\%) for recurrent bleeding. Total enteroscopy was achieved in $6 \%(n=11)$ of the cohort. The overall diagnostic and therapeutic yields of repeat BAE were $55 \%(n=96)$ and $42 \%(n=73)$, respectively. Angioectasia $(n=$ 65 ) was the most common finding in the majority of patients. Multiple angioectasias were noted in 38 patients and active bleeding was observed in 20 of these patients. Treatment modalities included: thermal $(n=56)$, mechanical therapy with through-the-scope clips ( $n=3)$, and combination/other $(n=14)$ ( $\triangleright$ Table 2$)$. Initial CE and repeat BAE agreed in $63 \%(n=84)$. In $27 \%(n=36)$, the initial CE was positive and the repeat BAE was 
- Table 1 Characteristics at initial BAE.

\begin{tabular}{|c|c|}
\hline Characteristic & Value $(n=175)$ \\
\hline Age, years & $64.1 \pm 16.3$ \\
\hline Male, n (\%) & $97(55 \%)$ \\
\hline \multicolumn{2}{|l|}{ Clinical presentation, n (\%) } \\
\hline - Melena & $71(40 \%)$ \\
\hline - Hematochezia & $17(10 \%)$ \\
\hline - Occult & $87(50 \%)$ \\
\hline \multicolumn{2}{|l|}{ Medical comorbidities ${ }^{1}, \mathrm{n}(\%)$} \\
\hline - Cardiac & $57(33 \%)$ \\
\hline - CKD & $36(21 \%)$ \\
\hline - Liver cirrhosis & $10(6 \%)$ \\
\hline - COPD & $24(14 \%)$ \\
\hline \multicolumn{2}{|l|}{ Medications ${ }^{1}, \mathrm{n}(\%)$} \\
\hline - ASA & $63(36 \%)$ \\
\hline - NSAID & $9(5 \%)$ \\
\hline - Warfarin & $33(19 \%)$ \\
\hline - Clopidogrel & $14(8 \%)$ \\
\hline Capsule endoscopy, n (\%) & $134(76 \%)$ \\
\hline - Angioectasia & $32(24 \%)$ \\
\hline - Active bleeding & $43(32 \%)$ \\
\hline - Ulcer & $13(10 \%)$ \\
\hline - Mass & $4(3 \%)$ \\
\hline - Negative & $42(31 \%)$ \\
\hline CTE, n (\%) & $72(30 \%)$ \\
\hline - Angioectasia & $22(31 \%)$ \\
\hline - Active bleeding & $3(4 \%)$ \\
\hline - Inflammation & $5(7 \%)$ \\
\hline - Mass & $3(4 \%)$ \\
\hline - Negative & $39(54 \%)$ \\
\hline \multicolumn{2}{|l|}{ Initial BAE, n (\%) } \\
\hline - Inpatient & $126(72 \%)$ \\
\hline - DBE & $162(93 \%)$ \\
\hline - Antegrade & $136(78 \%)$ \\
\hline \multicolumn{2}{|l|}{ Findings on initial BAE, $\mathrm{n}(\%)$} \\
\hline - Angioectasia & $75(43 \%)$ \\
\hline - Ulcer & $4(2 \%)$ \\
\hline - Other & $6(4 \%)$ \\
\hline - Not successful/aborted ${ }^{2}$ & $9(5 \%)$ \\
\hline - Negative & $81(46 \%)$ \\
\hline
\end{tabular}

- Table 1 (Continuation)

\section{Characteristic}

Value $(n=175)$

BAE therapeutic interventions, $\mathrm{n}(\%)$

\begin{tabular}{l|c|}
\hline - Thermal (APC, bipolar) & $72(89 \%)$ \\
\hline - Mechanical (through-the-scope clips) & $2(2 \%)$ \\
\hline - Combination thermal and mechanical & $7(9 \%)$ \\
\hline
\end{tabular}

APC, argon plasma coagulation; ASA, aspirin; BAE, balloon assisted enteroscopy; CKD, chronic kidney disease, COPD, chronic obstructive pulmonary disease; CTE, computed tomography enterography; DBE, double balloon enteroscopy; NSAID, non-steroidal anti-inflammatory drugs.

${ }^{1}$ More than 1 possible per patient.

${ }^{2}$ Exam could not be completed due to fixation of bowel or poor bowel preparation.

- Table 2 Repeat BAE findings and endotherapy.

\begin{tabular}{l|c|}
\hline Characteristic & Value (n=175) \\
\hline Repeat BAE findings, $\mathrm{n}(\%)$ & \\
\hline - Angioectasia & $65(37 \%)$ \\
\hline - Ulcer & $18(10 \%)$ \\
\hline - Mass/polyp & $5(3 \%)$ \\
\hline - Other & $8(5 \%)$ \\
\hline - Not successful/aborted ${ }^{1}$ & $10(6 \%)$ \\
\hline - Negative & $69(39 \%)$ \\
\hline Repeat BAE therapeutic interventions, $n(\%)$ & \\
\hline - Thermal (APC, bipolar) & $56(32 \%)$ \\
\hline - Mechanical (through-the-scope clips) & $3(2 \%)$ \\
\hline - Combination thermal and mechanical & $10(6 \%)$ \\
\hline - Other & $4(2 \%)$ \\
\hline $\begin{array}{l}\text { APC, argon plasma coagulation; BAE, balloon assisted enteroscopy. } \\
\text { 1Exam could not be completed due to fixation of bowel or poor bowel } \\
\text { preparation. }\end{array}$
\end{tabular}

negative, while in $10 \%(n=14)$, the initial CE was negative and the repeat BAE was positive. The Cohen's kappa statistic for agreement was 0.22 .

BAE adverse events were noted in $5 \%(n=8)$ of patients. These included self-limited abdominal pain and distension without evidence of perforation or pancreatitis $(n=5)$, self-limited hematemesis $(n=1)$, nausea and vomiting $(n=1)$, and chest pain with demand ischemia $(n=1)$, all of which resulted in hospitalization of five patients for observation.

\section{Predictors of positive repeat $\mathrm{BAE}$}

In comparing repeat BAE patients with a positive and negative exam, no statistically significant difference was noted in terms of gender, overt GIB, and anti-thrombotic medication use $(\triangleright$ Table 3$)$. Patients with a positive exam were significantly older than the negative group $(68.6 \pm 13.9$ vs. $60.9 \pm 17.1 ; P=$ 
- Table 3 Predictors of positive repeat BAE.

\begin{tabular}{|c|c|c|c|}
\hline Characteristic & $\begin{array}{l}\text { Therapeutic } \\
(n=73)\end{array}$ & $\begin{array}{l}\text { Negative } \\
(n=102)\end{array}$ & $P$ value \\
\hline Age, years & $68.6 \pm 13.9$ & $60.9 \pm 17.1$ & 0.001 \\
\hline Male, n (\%) & $41(56.2 \%)$ & $56(54.9 \%)$ & 0.87 \\
\hline Clinical presentation, n (\%) & & & 0.27 \\
\hline - Melena & $32(44 \%)$ & $40(39 \%)$ & \\
\hline - Hematochezia & $4(5 \%)$ & $13(13 \%)$ & \\
\hline - Occult & $37(51 \%)$ & $49(48 \%)$ & \\
\hline \multicolumn{4}{|l|}{ Medical comorbidities, n (\%) } \\
\hline - Cardiac & $32(43.8 \%)$ & $25(24.5 \%)$ & 0.01 \\
\hline . CKD & $21(28.8 \%)$ & $15(14.7 \%)$ & 0.04 \\
\hline - Cirrhosis & $5(6.9 \%)$ & $5(4.9 \%)$ & 0.58 \\
\hline - COPD & $16(21.9 \%)$ & $8(7.9 \%)$ & 0.01 \\
\hline \multicolumn{4}{|l|}{ Medications, n (\%) } \\
\hline - ASA & $32(43.8 \%)$ & $31(30.4 \%)$ & 0.07 \\
\hline - NSAID & $4(5.5 \%)$ & $5(4.9 \%)$ & 0.86 \\
\hline " Warfarin & $13(17.8 \%)$ & $20(19.6 \%)$ & 0.76 \\
\hline - Clopidogrel & $9(12.3 \%)$ & $5(4.9 \%)$ & 0.07 \\
\hline \multicolumn{4}{|l|}{ Initial BAE details, n (\%) } \\
\hline - Inpatient & $22(30 \%)$ & $27(26 \%)$ & 0.60 \\
\hline - DBE & $69(94 \%)$ & $93(91 \%)$ & 0.40 \\
\hline - Antegrade & $55(75 \%)$ & $81(79 \%)$ & 0.52 \\
\hline - Positive therapeutic yield & $47(64 \%)$ & $34(33 \%)$ & $<0.001$ \\
\hline \multicolumn{4}{|l|}{ Repeat BAE details, n (\%) } \\
\hline - Median time to repeat BAE, days (range) & $58(0-1758)$ & $28(0-1198)$ & 0.02 \\
\hline - Inpatient & $24(32.9 \%)$ & $30(29.4 \%)$ & 0.62 \\
\hline . DBE & $71(97.3 \%)$ & $96(94.1 \%)$ & 0.33 \\
\hline - Antegrade & $46(63 \%)$ & $35(34.3 \%)$ & $<0.001$ \\
\hline
\end{tabular}

$0.001)$, more likely to have cardiac comorbidities $(43.8 \%$ vs. 24.5\%; OR 2.4, 95\%Cl: 1.3-4.6; $P=0.01)$, CKD (28.8\% vs. $14.7 \%$; OR $2.3,95 \% \mathrm{Cl}: 1.1-4.9 ; P=0.04)$, and COPD $(21.9 \%$ vs. $7.9 \%$; OR 3.3 , $95 \% \mathrm{Cl}: 1.3-8.1 ; P=0.01)$.

Diagnostic initial CE and CTE was noted in $70 \%$ of patients with a positive exam compared to $59 \%$ in the negative group $(P=0.18)$. Furthermore, a positive repeat BAE was significantly associated with a positive initial BAE (64\% vs. $33 \%$; OR 3.6 , $95 \% \mathrm{Cl}: 1.9-6.8 ; P<0.001)$ and performing the procedure via the antegrade route ( $63 \%$ vs. $34.3 \%$; OR 3.3, 95\%Cl: $1.7-6.1$; $P<0.001)$ ( $\triangleright$ Table 3$)$.

On multivariable regression analysis, positive initial BAE (OR $=2.63, P=0.005)$ and antegrade route $(O R=2.46, P=0.009)$ were the only statistically significant predictive factors ( $>$ Table 4). However, the multivariable model containing patient age, cardiac comorbidities, CKD, positive initial CE/CTE results, diagnostic initial BAE, and antegrade repeat BAE demonstrated good discriminatory ability for predicting a positive repeat BAE (c-statistic 0.76) ( Fig. 1).

\section{Discussion}

Our study demonstrated that repeat BAE had moderate diagnostic and therapeutic yields of $55 \%$ and $42 \%$, respectively, which were comparable to initial BAE yields. Repeat BAE was also safe with a low rate of adverse events. A positive initial 
- Table4 Multivariable logistic regression model for positive repeat BAE.

\begin{tabular}{|l|l|l|l|}
\hline Risk factor & Odds Ratio & $\mathbf{9 5 \% C l}$ & $\mathbf{P}$ value \\
\hline Age (per 5 years) & 1.08 & $(0.96,1.23)$ & 0.20 \\
\hline Positive initial BAE & 2.63 & $(1.34,5.20)$ & 0.005 \\
\hline Antegrade route on repeat BAE & 2.47 & $(1.26,4.83)$ & 0.009 \\
\hline Cardiac comorbidities & 1.61 & $(0.77,3.36)$ & 0.20 \\
\hline CKD & 1.80 & $(0.75,4.31)$ & 0.19 \\
\hline Diagnostic initial CE/CTE & 0.33 \\
\hline $\begin{array}{l}\text { BAE, balloon assisted enteroscopy; CE, capsule endoscopy; CKD, chronic kidney disease; CTE, computed tomography enterography. } \\
\text { 1 Positive indicates the finding of a bleeding source (active bleeding, angioectasia, ulcer, mass, inflammation). }\end{array}$ \\
\hline
\end{tabular}

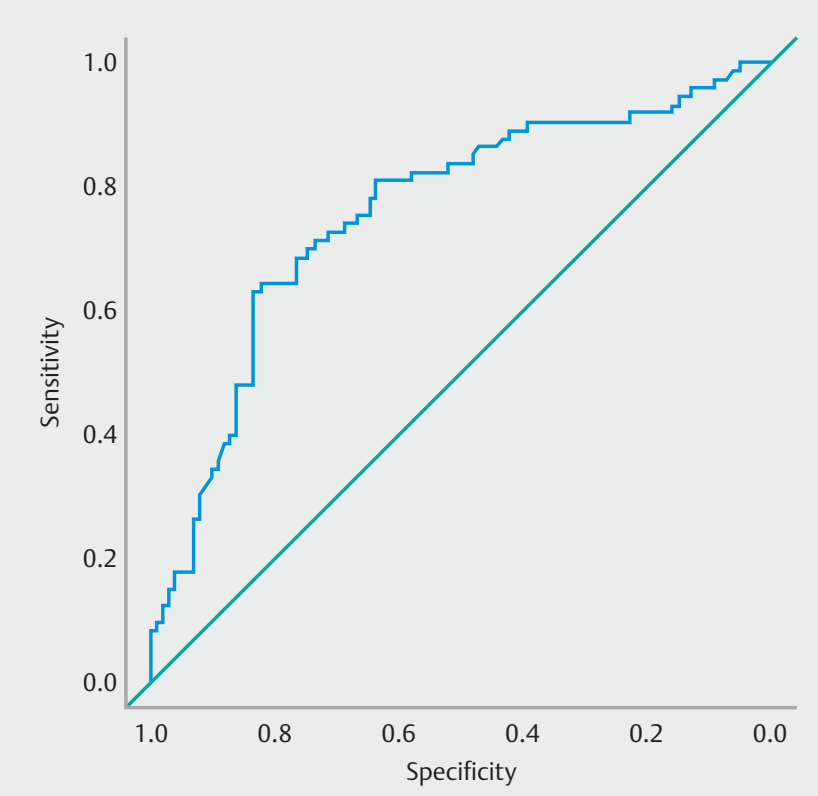

- Fig. 1 Receiver operating characteristic (ROC) curve of the multivariable model in predicting a positive repeat balloon assisted enteroscopy (BAE) showing an area under the curve (AUC) of 0.76 .

$B A E$ and antegrade route were predictive of a positive repeat BAE. Angioectasia remained the most common finding and thermal modality the most frequently utilized endotherapy.

BAE continues to play a key role in the management of smallbowel bleeding. The diagnostic yield of BAE in the setting of GIB is reported to be between $64 \%$ and $94 \%$ [10 - 14]. A meta-analysis demonstrated an increase in the yield of DBE from $28 \%$ to $75 \%$ if performed after a positive rather than a negative CE [15]. The timing of BAE has also been shown to influence the overall diagnostic yield. BAE performed within 24 and 72 hours of overt GIB had an overall diagnostic yield of $94 \%$ and $72 \%$, respectively $[16,17]$. The diagnostic and therapeutic yields of DBE and SBE were comparable across all indications [18].

More importantly, BAE has been shown to improve clinical outcomes. A prospective study of patients with obscure GIB with a positive CE treated with BAE demonstrated a significant reduction in bleeding and blood transfusion requirements [19]. However, long-term follow-up studies have demonstrated a substantial rebleeding rate in this patient population ranging from $40 \%$ to $46 \%$ over a mean follow-up period of 30 to 55 months [6-8]. Even after a negative BAE, the rebleeding rate can be as high as 38\% [20]. Cardiac comorbidities and overt initial bleeding have been identified as independent risk factors for rebleeding [21].

The adverse event rate of DBE and SBE is reported to be approximately $1 \%$ [22]. A large study of almost 4000 DBE procedures reported complications in 48 patients (1.2\%) [23]. Similarly, another study of about 2400 DBE procedures noted a complication rate of $1.7 \%$ [24]. Although we report a higher adverse event rate of $5 \%$ with abdominal pain and distension described in most patients, this can be attributed to the use of room air for luminal insufflation before converting to carbon dioxide. In our cohort, there were no cases of pancreatitis or perforation.

The optimal management strategy for patients with recurrent small-bowel bleeding remains unclear and is not well delineated in the literature. Byeon et al. studied 32 patients with recurrent small-bowel bleeding who underwent repeat DBE, noting a therapeutic yield of $53 \%$ [9]. As in our study, having a positive initial BAE was associated with a positive repeat BAE ( $P$ $<0.001$ ), while overt versus occult clinical presentation did not affect the yield of repeat BAE as demonstrated in our study.

This study is limited by its retrospective design, single center experience, and physician referral bias. Our patient population was heterogeneous in terms of median time to repeat BAE and, as such, etiology of rebleeding over this time interval may differ (e. g. missed lesion in early rebleeding versus development of new angioectasia in delayed rebleeding). In addition, clinical outcomes such as transfusion requirement and rebleeding rate after repeat BAE were not assessed due to incomplete follow-up given our referral patient population.

To the best of our knowledge, this is the largest study on the outcomes of repeat BAE in patients with small-bowel bleeding. The results are clinically impactful in identifying patient-related characteristics and endoscopic findings associated with a positive repeat $B A E$.

In conclusion, performing a repeat BAE should be considered for small-bowel bleeding as it appears safe with modest diag- 
nostic and therapeutic yields that were comparable to the initial BAE procedure. Angioectasia remained the most common finding and thermal endotherapy the most frequently used modality. Positive initial BAE and an antegrade route were significantly associated with a positive repeat BAE.

\section{Competing interests}

None

\section{References}

[1] Gerson LB, Fidler JL, Cave DR et al. ACG Clinical Guideline: Diagnosis and management of small bowel bleeding. Am J Gastroenterol 2015; 110: 1265 - 1287; quiz 1288

[2] Longstreth GF. Epidemiology and outcome of patients hospitalized with acute lower gastrointestinal hemorrhage: a population-based study. Am J Gastroenterol 1997; 92: 419-424

[3] Katz LB. The role of surgery in occult gastrointestinal bleeding. Semin Gastrointest Dis 1999; 10: $78-81$

[4] Gralnek IM. Obscure-overt gastrointestinal bleeding. Gastroenterology $2005 ; 128: 1424-1430$

[5] Yamamoto H, Sekine $Y$, Sato $\mathrm{Y}$ et al. Total enteroscopy with a nonsurgical steerable double-balloon method. Gastrointest Endosc 2001; 53: $216-220$

[6] May A, Friesing-Sosnik T, Manner $\mathrm{H}$ et al. Long-term outcome after argon plasma coagulation of small-bowel lesions using double-balloon enteroscopy in patients with mid-gastrointestinal bleeding. Endoscopy 2011; 43: 759-765

[7] Samaha E, Rahmi G, Landi B et al. Long-term outcome of patients treated with double balloon enteroscopy for small bowel vascular lesions. Am J Gastroenterol 2012; 107: 240-246

[8] Gerson LB, Batenic MA, Newsom SL et al. Long-term outcomes after double-balloon enteroscopy for obscure gastrointestinal bleeding. Clin Gastroenterol Hepatol 2009; 7: 664-669

[9] Byeon JS, Mann NK, Jamil LH et al. Is a repeat double balloon endoscopy in the same direction useful in patients with recurrent obscure gastrointestinal bleeding? J Clin Gastroenterol 2013; 47: 496 - 500

[10] Zhi FC, Yue H, jiang B et al. Diagnostic value of double balloon enteroscopy for small-intestinal disease: experience from China. Gastrointest Endosc 2007; 66: S19-21

[11] Zhong J, Ma T, Zhang $C$ et al. A retrospective study of the application on double-balloon enteroscopy in 378 patients with suspected smallbowel diseases. Endoscopy 2007; 39: 208 - 215
[12] Cazzato IA, Cammarota G, Nista EC et al. Diagnostic and therapeutic impact of double-balloon enteroscopy (DBE) in a series of $100 \mathrm{pa}$ tients with suspected small bowel diseases. Dig Liver Dis 2007; 39: $483-487$

[13] Manabe N, Tanaka S, Fukumoto A et al. Double-balloon enteroscopy in patients with Gl bleeding of obscure origin. Gastrointest Endosc 2006; 64: $135-140$

[14] Arakawa D, Ohmiya N, Nakamura M et al. Outcome after enteroscopy for patients with obscure GI bleeding: diagnostic comparison between double-balloon endoscopy and videocapsule endoscopy. Gastrointest Endosc 2009; 69: 866-874

[15] Teshima CW, Kuipers EJ, van Zanten SV et al. Double balloon enteroscopy and capsule endoscopy for obscure gastrointestinal bleeding: an updated meta-analysis. J Gastroenterol Hepatol 2011; 26: 796 801

[16] Monkemuller K, Neumann $\mathrm{H}$, Meyer $\mathrm{F}$ et al. A retrospective analysis of emergency double-balloon enteroscopy for small-bowel bleeding. Endoscopy 2009; 41: 715-717

[17] Aniwan S, Viriyautsahakul V, Rerknimitr R et al. Urgent double balloon endoscopy provides higher yields than non-urgent double balloon endoscopy in overt obscure gastrointestinal bleeding. Endosc Int Open 2014; 2: E90 -E95

[18] Lipka S, Rabbanifard R, Kumar A et al. Single versus double balloon enteroscopy for small bowel diagnostics: a systematic review and meta-analysis. J Clin Gastroenterol 2015; 49: 177 - 184

[19] Kaffes AJ, Siah C, Koo JH. Clinical outcomes after double-balloon enteroscopy in patients with obscure GI bleeding and a positive capsule endoscopy. Gastrointest Endosc 2007; 66: 304-309

[20] Shinozaki S, Yano T, Sakamoto $\mathrm{H}$ et al. Long-term outcomes in patients with overt obscure gastrointestinal bleeding after negative double-balloon endoscopy. Dig Dis Sci 2015; 60: 3691-3696

[21] Rahmi G, Samaha E, Vahedi K et al. Long-term follow-up of patients undergoing capsule and double-balloon enteroscopy for identification and treatment of small-bowel vascular lesions: a prospective, multicenter study. Endoscopy 2014; 46: 591 - 597

[22] Khashab MA, Pasha SF, Muthusamy VR et al. The role of deep enteroscopy in the management of small-bowel disorders. Gastrointest Endosc 2015; 82: 600-607

[23] Moschler O, May AD, Muller MK et al. [Complications in double-balloon-enteroscopy: results of the German DBE register]. Z Gastroenterol 2008; 46: $266-270$

[24] Mensink PB, Haringsma J, Kucharzik T et al. Complications of double balloon enteroscopy: a multicenter survey. Endoscopy 2007; 39: $613-615$ 